\title{
Chapter 22: Analytics of Learner Video Use
}

\author{
Negin Mirriahi', Lorenzo Vigentini²
}

'School of Education \& Teaching Innovation Unit, University of South Australia, Australia
${ }^{2}$ School of Education \& PVC (Education Portfolio), University of New South Wales, Australia
DOI: $10.18608 /$ hla17.022

\begin{abstract}
Videos are becoming a core component of many pedagogical approaches, particularly with the rise in interest in blended learning, flipped classrooms, and massive open and online courses (MOOCs). Although there are a variety of types of videos used for educational purposes, lecture videos are the most widely adopted. Furthermore, with recent advances in video streaming technologies, learners' digital footprints when accessing videos can be mined and analyzed to better understand how they learn and engage with them. The collection, measurement, and analysis of such data for the purposes of understanding how learners use videos can be referred to as video analytics. Coupled with more traditional data collection methods, such as interviews or surveys, and performance data to obtain a holistic view of how and why learners engage and learn with videos, video analytics can help inform course design and teaching practice. In this chapter, we provide an overview of videos integrated in the curriculum including an introduction to multimedia learning and discuss data mining approaches for investigating learner use, engagement with, and learning with videos, and provide suggestions for future directions.
\end{abstract}

Keywords: Video, analytics, learning, instruction, multimedia

With the rise in online and blended learning, massive open and online courses (MOOCs) and flipped classroom approaches, the use of video has seen a steady increase. Although much research has been done, particularly focusing on psychological aspects, the educational value, and the user experience, the advancements of the technology and the emergence of analytics provide an opportunity to explore and integrate not only how videos are used in the curriculum but whether their adoption has contributed towards learner engagement or learning (Giannakos, Chorianopoulos, \& Chrisochoides, 2014). Educators are choosing to bring videos into their courses in a variety of ways to meet their particular intentions. This is occurring not only in higher education, continuing professional development, and the $\mathrm{K}-12$ sectors but also in corporate and government training (Ritzhaupt, Pastore, \& Davis, 2015). Therefore, it is important to evaluate or investigate how learners are using and engaging with videos in order to inform future modifications or advances in how they are integrated into the curriculum.

The use of videos in the curriculum stems from earlier use of multimedia in learning environments dat- ing back several decades. Hence, before exploring how videos are integrated into the curriculum or identifying methods to investigate how learners use them, it is important to consider prior research conducted on multimedia learning. This chapter begins with a discussion of related work, specifically multimedia learning and strategies for evaluating learning with multimedia. This is followed by methodological considerations including video types, the ways videos can be integrated into the curriculum, and the data mining approaches that can be applied to understand use, engagement, and learning with videos. The final section summarizes the chapter and offers directions for further exploration.

\section{RELATED WORK}

\section{What Do We Know about Learning with Multimedia and Interactive Courseware?}

"People learn better from words and pictures than from words alone" is the key statement driving the popular work of Mayer (2009) on multimedia learning. Videos are a form of multimedia and therefore this chapter 
will leverage a wealth of research exploring their effectiveness for learning. Since the introduction of computers and instructional technology in education, both the research on and the development of interactive course materials, followed the trends and shifts of beliefs in psychological and educational research and can be identified within one of the following three phases/perspectives:

1. Behaviourist: presenting an objectivist view of knowledge and instructional design features focusing on serial structuring of material, program/ delivery control, and regular review and testing against specified criteria - from Skinner's (1950) radical behaviourism to Gagne's (1965) tenets on the conditions of learning.

2. Cognitive: focusing on the factors affecting effective learning and teaching with attention to information processing and the characteristics of the learner, the teachers, and the learning environment (Keller, 1967; McKeachie, 1974).

3. Constructivist: knowledge-building with a focus on the interdependence of social and individual processes in the co-construction of knowledge (Palincsar, 1998).

In between these often entrenched perspectives, the key issue has been the definition of how much instruction affects learning (Lee \& Anderson, 2013) and, in particular, how much the instructivist and constructivist approaches deriving from the three perspectives facilitate active learning. According to the behavioural perspective, learning can be efficiently accomplished with a strong set of instructions and a specific sequence of learning (Kirschner, Sweller, \& Clark, 2006; Lee \& Anderson, 2013) but there may be a trade-off between efficiency and effectiveness (Atkins, 1993). Instead, the key weakness of the cognitive orientation is the articulation or provision of suitable metacognitive frameworks to support learning. Constructivist and connectivist models of learning are student-centred in nature and imply a level of self-directedness and self-regulation in order to navigate through the teaching material to determine the most suitable learning pathway. Notwithstanding the philosophical perspective taken, "what seems to be missing are models of learning appropriate for the design opportunities offered by new technologies" (Atkins, 1993, p. 252) and this includes videos and multimedia.

Practitioners and instructional designers find comfort in Gagne's (1965) model of instructional events and his classification of types of learning outcomes because of their relative ease of adoption and use (Reeves, 1986). Furthermore, the concept of mastery learning (Bloom, 1968) has attracted a large amount of research supporting its effectiveness (Guskey \& Good, 2009; Kulik, Kulik, \& Bangert-Drowns, 1990) and together with the five main elements of Keller's (1967) Personalized System of Instruction (PSI), as noted in Figure 22.1, strongly influenced instructional design and learning sciences.

Mayer (2009) attempts to summarize the wealth of knowledge on multimedia learning accrued over the past four decades in the formulation of 12 principles, as noted in Figure 22.2. These principles provide insight into the way people learn with multimedia, grounded in evidence from psychology, instructional design, and the learning sciences. Being aware of the positive and negative design features and their known effects on learning is very important when an instructor is integrating videos into their teaching.

Another aspect to consider, described in more detail below in Data-Mining Approaches to Videos, is the issue of engagement and how learning relates to patterns of engagement. Although Mayer and colleagues demonstrated the effects of certain features of the medium on learning, when moving from a lab context to real life, the extent to which a learner interacts with the medium is an important aspect. This is mediated not only by the characteristics of the medium, but also by the individual preferences and approaches to learning, which make it quite hard to clearly disentangle the relation between the volume or amount of engagement with videos (i.e., the interaction) and the learning, which is tied to the mode of assessing learning.

- $\quad$ The go-at-your-own-pace feature, which permits a learner to move through the course at a speed commensurate with his ability and other demands upon his time

- The unit-perfection requirement for advancement, which lets the learner advance to new material only after demonstrating mastery of that which preceded

- The use of lectures and demonstrations as vehicles of motivation, rather than sources of critical information

- The related stress upon the written word in teacher-learner communication

- $\quad$ The use of proctors, which permits repeated testing, immediate scoring, almost unavoidable tutoring, and a marked enhancement of the personal-social aspect of the educational process

Figure 22.1. Keller's (1967) elements of the PSI (Personalized System of Instruction). 
1. Coherence Principle - People learn better when extraneous words, pictures, and sounds are excluded rather than included.

2. Signalling Principle - People learn better when cues that highlight the organization of the essential material are added.

3. Redundancy Principle - People learn better from graphics and narration than from graphics, narration, and on-screen text

4. Spatial Contiguity Principle - People learn better when corresponding words and pictures are presented near rather than far from each other on the page or screen.

5. Temporal Contiguity Principle - People learn better when corresponding words and pictures are presented simultaneously rather than successively.

6. Segmenting Principle - People learn better from a multimedia lesson, which is presented in user-paced segments rather than as a continuous unit.

7. Pre-training Principle - People learn better from a multimedia lesson when they know the names and characteristics of the main concepts.

8. Modality Principle - People learn better from graphics and narrations than from animation and on-screen text.

9. Multimedia Principle - People learn better from words and pictures than from words alone.

10. Personalization Principle - People learn better from multimedia lessons when words are in conversational style rather than formal style.

11. Voice Principle - People learn better when the narration in multimedia lessons is spoken in a friendly human voice rather than a machine voice.

12. Image Principle - People do not necessarily learn better from a multimedia lesson when the speaker's image is added to the screen.

Figure 22.2. Mayer's (2009) multimedia design principles.

\section{Key Considerations in the Multimedia Literature}

A recent review of the literature on video-based learning between 2003-2013 (Yousef, Chatti, \& Schroeder, 2014) provided a useful overview of the types of studies conducted. This categorization is reproduced in Figure 22.3 below.

This provides a good starting point to make sense of the most recent research directions, but mostly ignores the research produced in the previous five decades, culminating in Mayer (2009), who identifies six major strands relevant to multimedia and video in learning and education: 1) perception and attention; 2) working memory and memory capacity; 3) cognitive load theory; 4) knowledge representation and integration; 5) learning and instruction (including learning styles, approaches, and instructional methods); and 6) self-regulation of learning. These areas provide the theoretical backdrop necessary to understand, identify, and select adequate analytics (intended here as both methods and metrics) to demonstrate the effectiveness of videos for learning. In particular, work done on the first three areas provides essential parameters to determine the way in which a learner may interact and engage with videos, and the second set of three provides useful data to understand the way in which learning from and with videos occurs, all illustrated in Figure 22.4.

Relating back to the taxonomy of Yousef and colleagues (2014), the notion of effectiveness fits in the broader learning space (Figure 22.4) and is at the centre of the discussion and the evaluation of how effectiveness can
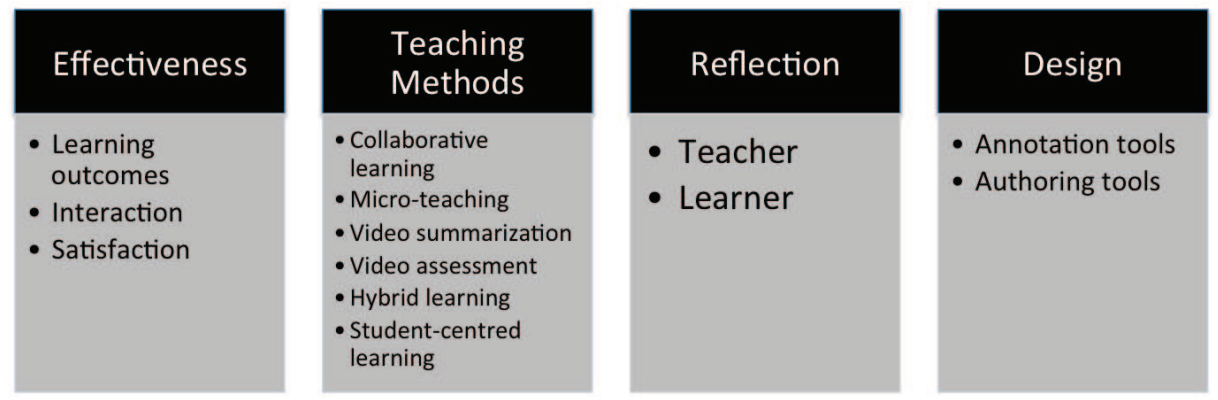

Figure 22.3. Overview of the video-based literature 2003-2013 (adapted from Yousef et al., 2014). 
be applied to instruction, the learners, and the tools (specifically videos). There is a direct connection between instruction and the learner: this is exemplified in what an instructor does to facilitate learning to respond to the learners, represented under teaching methods as noted in Figure 22.3 (Yousef et al., 2014). Furthermore this is extended in Figure 22.4 to illustrate the relationship between both instruction and the learner and instruction and the learning tools - i.e., the video. In the interaction between instruction and the learner, elements such as learning styles, approaches, and instructional methods alongside self-regulated learning affect the effectiveness of instruction and learning. Instruction is affected by the instructional methods and cognitive load, and multimedia learning theory. The direct relation between the instruction and the instructional tools such as the resources, activities, supporting and evaluation tools - in this particular case the use of videos - is partly present in Yousef and colleagues' (2014) taxonomy under "design," but the important reference to the learner is missing, especially when students not only consume videos, but also produce them (Juhlin, Zoric, Engström, \& Reponen, 2014). Finally, the dual relationship between the learning and the video is affected by learners' perception, attention, their working memory and capacity as well as their preferences driven by the affordances of the videos. Figure 22.4 also shows some key metrics that could be applied to investigate the relationships between instruction, the learner, and the video when measuring effectiveness.

\section{Evaluation Methods to Investigate the Effectiveness of Videos on Learning}

In order to evaluate the effectiveness of multimedia and videos, together with experimental (e.g., lab) studies, a plethora of published research proposes a comparative approach (see Data-Mining Approaches to Videos below), or a "horserace" model for evaluating the comparison of a mythical "traditional instruction" with the latest innovations in instructional technology tools (Reeves, 1986, 1991). Although experimental studies have a certain appeal and credibility, research studies adopting experimental or quasi-experimental designs comparing instructional technologies have produced very few useful outcomes. Literature reviews and meta-analyses have recognized this phenomenon as the "no significant differences" problem (Joy \& Garcia, 2000; Oblinger \& Hawkins, 2006; Russell, 1999). Videos have been subjected to similar comparative studies since the 1980 s - initially with a focus on videodiscs and interactive videos, and later with computer-based instruction, video animations, documentaries, and video-recorded presentations or lectures. The debate on the influence of media on learning has been well represented by the opposing views of Clark $(1983,1994)$ and (Kozma, 1991, 1994). Clark (1994) argues that media does not influence learning under any condition; however, "learning is caused by the instructional methods embedded in the media presentation" (p. 26). Notably, instructional methods were defined as "any way to shape information that activates, supplants, or compensates for the cognitive processes necessary for achievement or motivation"

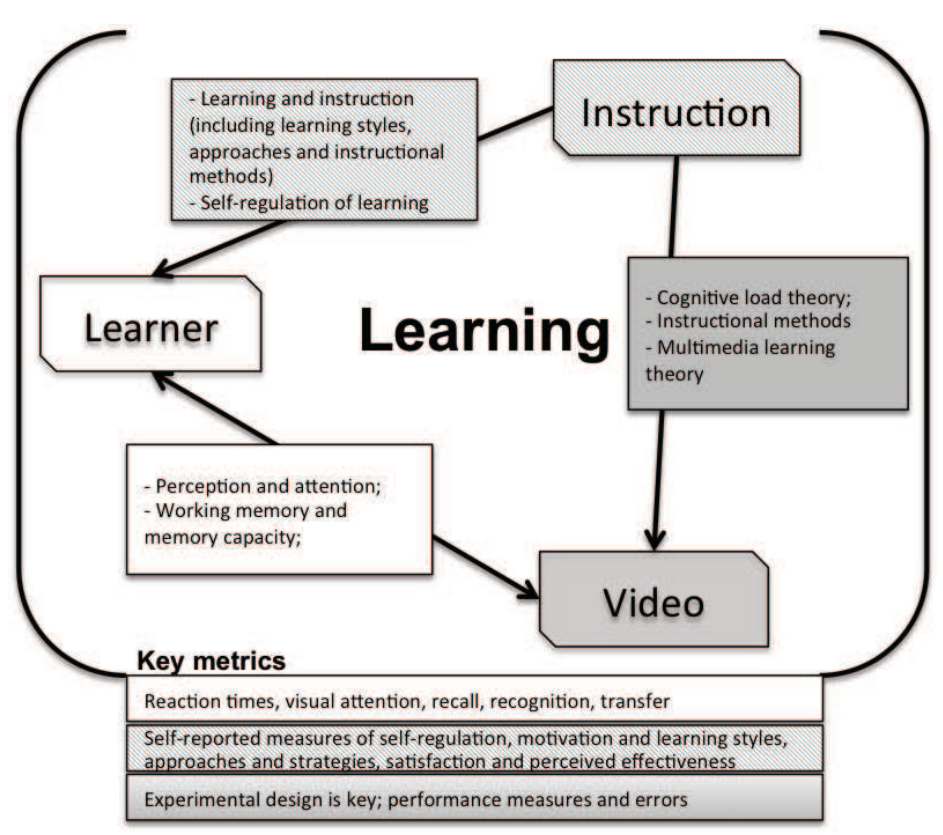

Figure 22.4. Interconnections between the learner, instruction, and video with reference to some of the key metrics used in the literature. 
(p. 23). On the other side of the debate, Kozma (1991, 1994) argues that media and methods are intertwined and dependent on each other:

From an interactionist perspective, learning with media can be thought of as a complementary process within which representations are constructed and procedures performed, sometimes by the learner and sometimes by the medium [...] media must be designed to give us powerful new methods, and our methods must take appropriate advantage of media's capabilities (1994, pp. 11, 16).

Within this "Great media debate," Tennyson (1994) argues, "a scientist is never satisfied with the current state of affairs, but is always and foremost challenged by extending knowledge" (p. 15). He asserts that a scientist turns into an advocate when statistically significant results are found and the newly found approach is adopted to tackle the world's complexity: this is termed the "big wrench" approach. "The advocate, with the big wrench in hand, sets out to solve, suddenly, a relatively restricted number of problems. That is, all of the formerly many diverse problems, now seem to be soluble with the new big wrench (or panacea)" (p. 16). This should provide a stark warning against the temptation of focusing too much or exclusively on one method of evaluation, (e.g., analytics) as the potential "big wrench" used to make sense of learning with and from videos in education. Instead, a range of approaches should be used to investigate and evaluate use, engagement, and learning with videos. Such strategies will be explored in Data-Mining Approaches to Videos, below.

\section{METHODOLOGICAL CONSIDER- ATIONS}

\section{Video Types}

Videos have become increasingly important to provide varied pedagogical opportunities to engage learners and respond to the growing need for flexible, blended, and online learning modes. There are two broad categories of video use: synchronous and asynchronous. The former provides a real-time opportunity for learners and instructors to engage with one another simultaneously through virtual classrooms, live webcasts, or video feeds. The latter supports self-paced learning and is primarily an individual interaction between the medium and the learner. Asynchronous videos are becoming more common and vary from the capture of an in-class lecture, to the recording of an educator's talking head or their audio of a lecture accompanied by slides or images illustrating core concepts (Owston, Lupshenyuk, \& Wideman, 2011). Such lecture videos can be a variety of durations and have become more mainstream with the introduction of automatic lecture recordings in many lecture halls facilitated by technologies such as Echo360 ${ }^{1}$, Opencast $^{2}$, and Kaltura ${ }^{3}$ minimizing the resources and time required of the educator to produce the videos. While in some learning contexts, these videos are provided to learners as supplemental resources, many educators are adopting flipped classroom approaches whereby information-transmission is done through required video lectures prior to class time, providing time in class for collaborative and active learning activities. Further, lecture videos have also gained momentum with their recent availability through streaming platforms such as YouTube, Apple's iTunes U program, and the Khan Academy where a vast variety of videos covering various disciplines and concepts are available. MOOCs have also contributed to the widespread adoption of lecture videos. For many MOOC providers (e.g., Coursera, Udacity, EdX), a core functionality is the provision of video streaming, providing much of the course content via videos supported by quizzes, forums, and readings (Diwanji, Simon, Marki, Korkut, \& Dornberger, 2014; Li, Kidzinski, Jermann, \& Dillenbourg, 2015). These particular MOOCs, which focus heavily on video lectures and individual mastery of content (e.g., via quizzes with immediate feedback), follow a cognitive-behaviourist approach, often referred to as xMOOCs (Conole, 2013), and have largely developed since 2012 (Margaryan, Bianco, \& Littlejohn, 2015). While in many cases higher education videos are the result of live recording with what is available (i.e., automatic lecture recording or desktop recording using screen capture and audio recording), in MOOCs, videos tend to be scripted, recorded, and edited with high-end equipment and slick production values (Guo, Kim, \& Rubin, 2014; Ilioudi, Giannakos, \& Chorianopoulos, 2013; Kolowich, 2013).

Lecture videos are not the only type of educational videos being integrated in the curriculum. Video recordings of learners' own performances or engagement with an activity are used for self-reflection, peer and instructor feedback, and goal-setting purposes. For example, pre-service teachers have viewed recordings of their own teaching scenarios and made notes or markers on particular segments for their own self-reflection purposes or to provide feedback to peers facilitated by video annotation software such as the Media Annotation Tool (MAT) (Colasante, 2010, 2011). The use of video recordings for learner reflection and critical analysis has also been used in medical education whereby learners view recordings of their consultations with simulated patients and explain their behaviour and note areas of improvement linked

\footnotetext{
${ }^{1}$ Echo360 Active Learning Platform http://echo360.com

${ }^{2}$ Opencast http://www.opencast.org

${ }^{3}$ Kaltura http://corp.kaltura.com
} 
to specific time-codes in the video using annotation software, DiViDU (Hulsman, Harmsen, \& Fabriek, 2009). In the performing arts discipline, videos of learners' own performances have been used for self-reflection purposes (Daniel, 2001) and more recently coupled with video annotation software, CLAS, for learners to make time-stamped and general comments related to their performance (Gašević, Mirriahi, \& Dawson, 2014; Mirriahi, Liaqat, Dawson, \& Gašević, 2016; Risko, Foulsham, Dawson, \& Kingstone, 2013).

\section{Video in the Curriculum}

Although videos are included in the curriculum in various ways, it is not often transparent whether the integration of videos into the course has been effective or requires further refinement. Whether as supplemental resources, core components of flipped classroom approaches or MOOCs, or used for reflective practice and peer feedback, it is important to understand how learners engage with the videos and how it contributes to their learning experience (Giannakos et al., 2014). To date, numerous studies have been conducted in various educational settings exploring the effectiveness of videos in the curriculum (Giannakos, 2013; Yousef et al., 2014). However many of the earlier studies have largely relied on learners' and educators' self-reports rather than objective data. Relying solely on self-reports can lead to potential inaccurate recall of learners' prior behaviour (Winne \& Jamieson-Noel, 2002) or lead to social-desirability bias whereby learners provide the expected response rather than the most accurate one (Beretvas, Meyers, \& Leite, 2002; Gonyea, 2005). Recent advances in learning analytics and data mining techniques, however, can provide more objective and authentic data regarding learners' actual use of learning technologies by analyzing their digital footprints (Greller \& Drachsler, 2012). Hence, mining the data from learners' use of videos as a complement to other data sources (e.g., assessment scores, surveys, etc.) (Giannakos, Chorianopoulos, \& Chrisochoides, 2015) can help begin to uncover how learners actually use videos and how they contribute to their learning experience. Leveraging the trace or clickstream data available from learners' use of videos, which can be termed video analytics, has become more readily available in recent years from streaming video platforms (YouTube, Vimeo) or MOOC providers (Udacity, Coursera, FuturLearn, EdX).

Broadly, we define video analytics as the collection, measurement, and analysis of data from learners' use of videos for the purposes of understanding how they engage with them in learning contexts. This provides the opportunity to mine learners' actual use of the videos alongside data collected from other online activities such as quizzes or annotations to explore when and how learners engage with the videos and their associated activities. Aggregating such data with performance measures (e.g., grades or scores) can help identify any impact on learning outcomes while collecting information about learners' intentions or motivations through self-reports can help explain learner use. Collectively, these varied data sets can help reveal whether learners are engaging or using video technologies as intended by the course design or if further revisions to the pedagogical approach are required to better meet the intended outcomes of the learning and teaching strategy (Pardo et al., 2015).

In the next section, we discuss various approaches to studying learner use of video technologies (using video analytics alongside other data collection methods) to begin to understand patterns in learning and engagement.

\section{DATA MINING APPROACHES TO VIDEOS}

Data mining is commonly defined as the process of collecting, searching through, and analyzing a large amount of computerized data, in order to discover patterns, trends, or relationships (Witten \& Frank, 2005; Romero \& Ventura, 2010; Peña-Ayala, 2014). This is done through a combination of tools and methods used in statistics and artificial intelligence (AI). The algorithms driving the mining process derive from a field of research in AI termed knowledge discovery and machine learning: the broad categories of machine learning and the algorithms associated with these are represented in Figure 22.5.

Data mining has long been used to study multimedia and video. This is partly because of the relative ease in creating new content and the availability of web-based video streaming services to distribute videos. When one looks at applications and mining techniques for videos, there are two major strands of work: 1) making sense of the content of the video and 2) exploring how learners use videos. In the next two sections, we will explore some of these methods and techniques.

Figure 22.5 provides an overview of the connections of machine learning algorithms and applications applicable to video analytics. It provides a distinction between supervised and unsupervised machine learning, leading to the specific types of algorithms used to analyze the data from different applications of video (e.g., learners' interaction with video content and their use of videos). Depending on the nature of the data sources (for example, usage and in-video behaviours, or frame analysis), different families of algorithms are more appropriate for making sense of the data.

In this chapter, we will not dwell on the effectiveness of algorithms, but briefly describe some applications 


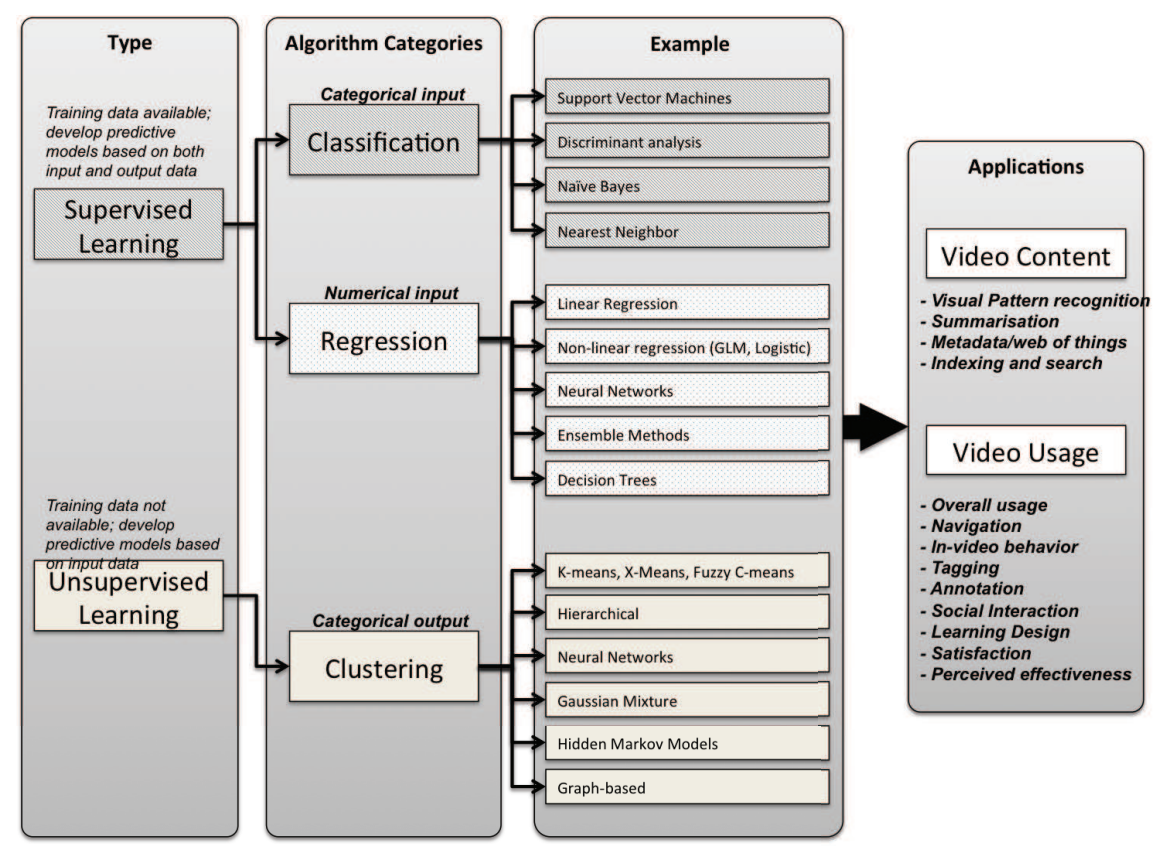

Figure 22.5. Interconnections between the learner, instruction, and video with reference to some of the key metrics used in the literature.

of video content mining, giving particular attention to usage. Table 22.1 provides an explicit mapping of existing literature, algorithms, types of interactions, and features used in the analysis.

\section{Mining Applied to Content}

Making sense of videos is a complex problem that leverages advances in automated content-based methodologies such as visual pattern recognition (Antani, Kasturi, \& Jain, 2002), machine learning (Brunelli, Mich, \& Modena, 1999), and human-driven action (Avlonitis, Karydis, \& Sioutas, 2015; Chorianopoulos, 2012; Risko et al., 2013). The latter can be individual use of video resources or the social metadata (tagging, sharing, and social engagement). Video indexing, commonly used to make sense of video content, is based on three main steps: 1) video parsing, 2) abstraction, and 3) content analysis (Fegade \& Dalal, 2014). Furthermore, given the exponential growth of video content, the problems of navigation (or searching within content) and summarization can also be resolved using content analytics (Grigoras, Charvillat, \& Douze, 2002; He, Grudin, \& Gupta, 2000).

The relevance of this work can be seen in the ability to characterize and present video content to learners and the methods to integrate this medium with teaching and instruction. For example, a better way of guiding learners to key points in a video or providing learners with ways to regulate their own learning with videos is to provide a navigational index much like a table of contents or glossary to allow learners to jump to the most relevant part of video. One way of providing this is using video annotation software, which provides instructors and learners with the option of flagging particular time-stamped parts of a video for later review and to gauge their learning in relation to others by viewing other's annotations or flags (Dawson, Macfadyen, Evan, Foulsham, \& Kingstone, 2012). Given that new users of websites and applications tend to watch videos and skip text while more expert users skip videos and scan the associated text (Johnson, 2011), this creates interesting design problems and questions: by aggregating learner engagement or use of videos, could the "crowd-sourced" expertise of learners provide automated or user-driven instructional support scaffolding novice or less experienced learners or is the adoption of machine learning more effective? Although there is much evidence in favour of machine driven methods (i.e., EDM and AIED communities), the problem of knowledge representation and transfer remains a crucial one.

Another source of accessible metadata about videos came about with assistive technologies and the synching of text transcripts related to videos. For example, Ed-X displays both video and transcripts on the same page, whilst YouTube has recently introduced an automatic caption tool to create subtitles.

\section{Mining Applied to Usage: Logs of Activity to Measure Interaction}

The extraction of trace or log data from learners' use of video technologies and the analysis to understand learning processes or engagement is still at an early stage both in terms of a research discipline (e.g., learning 
analytics and educational data mining) but also in terms of how it is used to inform teaching practice. As noted by Giannakos, Jaccheri, and Krogstie (2015), further experimentation with methodological approaches is needed to advance the area. Yet, there are a growing number of studies exploring how learners learn and engage with video technologies using educational data mining and learning analytics methods alongside more traditional data collection approaches (e.g., questionnaires, observations, and interviews). To provide an overview we specifically looked at published literature from 2000 onward mentioning video or multimedia learning. The additional criterion required was at least the use of one of the variables categorized under "usage" or "interaction," as described in the last section.

In Table 22.1, we introduce studies that have used such methods to explore learner use, engagement, and learning with videos. We have categorized the studies using the algorithm categories and application types noted on Figure 22.5.

In addition to the definition of each variable, the type of study or algorithm uses the same taxonomy presented earlier with studies that use the comparative approach or studies that apply data mining techniques classed using the schema in Figure 22.5. Notably, a "modelling" type, referring to work, has been added, which used the data and variables not to inform the learning and teaching per se, but to explain or describe the patterns of use and interaction with videos.

\section{Moving from Usage to Engagement}

As seen in the previous section, a number of studies investigate what learners do with videos. However, in order to characterize engagement in the context of learning and teaching, it is essential to consider what is meant by engagement with videos. For example, a learner could click on the play button of a video presented as part of a "flipped classroom" activity and then walk away to make coffee. The video would still be playing, and logging this activity as usage; however, the learner would be not be engaged with the activity. This poses a challenge when interpreting activity logs and makes the case for avoiding the "big wrench" approach mentioned earlier. The time spent on task is not simple to interpret in an ecologically valid setting; unlike in experimental conditions in which extraneous variables are controlled or monitored, real learning might occur in highly noisy conditions (for example, increasingly "on the go" from a mobile device on a busy commuter bus (Chen, Seilhamer, Bennett, \& Bauer, 2015).

However, expedients made available via modern web technologies can partly circumvent this problem. For example, including in-video quizzes (IVQ) provides an opportunity to check whether learners have understood concepts in the video or how they perceive its effectiveness. These not only provide a "pulse" on engagement, but also a view on the effectiveness of the videos for learning. Most MOOC providers offer some form of IVQs that can be inserted at specific points.

Table 22.1. Summary of Related Work using Video Analytics Techniquesmat

\begin{tabular}{|c|c|c|c|c|c|c|c|c|c|c|c|c|c|}
\hline \multirow[b]{2}{*}{ Reference } & \multirow[b]{2}{*}{$\begin{array}{l}\text { Type of study or } \\
\text { algorithm type }\end{array}$} & \multicolumn{3}{|c|}{ Usage } & \multicolumn{4}{|c|}{ Interaction } & \multicolumn{5}{|c|}{ Additional var. } \\
\hline & & 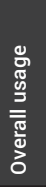 & $\begin{array}{l}\frac{5}{\mathrm{o}} \\
\frac{\mathrm{N}}{\mathrm{N}} \\
\frac{\mathrm{N}}{2}\end{array}$ & 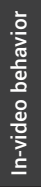 & 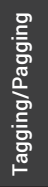 & 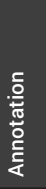 & 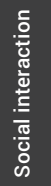 & 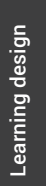 & 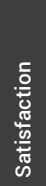 & 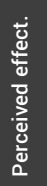 & 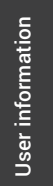 & 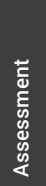 & 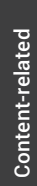 \\
\hline Anusha \& Shereen, 2014 & Classification & & & & & V & & & & & & $\mathrm{V}$ & \\
\hline Avlonitis \& Chorianopoulos, 2014 & Correlation & $\mathrm{v}$ & $\mathrm{v}$ & $\mathrm{v}$ & & & & & & & & & $\mathrm{v}$ \\
\hline Avlonitis, Karydis, \& Sioutas, 2015 & Correlation, Regression & v & v & 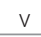 & & & & & & & & & $\mathrm{v}$ \\
\hline Brooks, Epp, Logan, \& Greer, 2011 & Clustering & $\mathrm{v}$ & v & $\vee$ & & & & & & v & & & \\
\hline Chen, Chen, Xu, March, \& Benford, 2008 & Comparison & & & & & V & & & & & & & $\mathrm{v}$ \\
\hline Chorianopoulos, 2012 & Comparison & $\mathrm{v}$ & & & 0 & & v & & & & & V & $\mathrm{v}$ \\
\hline Chorianopoulos, 2013 & Comparison & & V & $\mathrm{v}$ & & & & & & & & $\mathrm{V}$ & $\mathrm{v}$ \\
\hline $\begin{array}{l}\text { Chorianopoulos, Giannakos, Chrisochoides, \& Reed, } \\
2014\end{array}$ & Framework & v & V & v & & & & & & & & V & $\mathrm{v}$ \\
\hline Cobarzan \& Schoeffmann, 2014 & Comparison & & v & $\mathrm{v}$ & & & & & & & & V & $\mathrm{v}$ \\
\hline Coleman, Seaton, \& Chuang, 2015 & Modelling, Classification & $\mathrm{v}$ & & & & & & & & & & $\mathrm{v}$ & \\
\hline Crockford \& Agius, 2006 & Comparison & & v & v & & & & & & & & & $\mathrm{v}$ \\
\hline de Konig, Tabbers, Rikers, \& Paas, 2011 & Comparison & $\mathrm{v}$ & & $\mathrm{v}$ & & & & v & & & & & $\mathrm{v}$ \\
\hline Delen, Liew, \& Willson, 2014 & Comparison & & V & v & & & & & & & & & $\mathrm{v}$ \\
\hline Dufour, Toms, Lewis, \& Baecker, 2005 & Comparison & $\mathrm{v}$ & $\mathrm{V}$ & 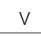 & & & & & $\mathrm{v}$ & & & & $\mathrm{v}$ \\
\hline Gašević, Mirriahi, \& Dawson, 2014 & Comparison & & & & & V & & v & & & & & \\
\hline Giannakos, Chorianopoulos, \& Chrisochoides 2014 & Comparison & & $\mathrm{V}$ & $\mathrm{v}$ & & & & & & v & & $\mathrm{V}$ & \\
\hline Giannakos, Chorianopoulos, \& Chrisochoides, 2015 & Modelling, Comparison & & $\mathrm{V}$ & $\mathrm{v}$ & & & & & $\mathrm{v}$ & $\mathrm{V}$ & & $\mathrm{V}$ & $\mathrm{V}$ \\
\hline
\end{tabular}


Table 22.1 (cont.). Summary of Related Work using Video Analytics Techniquesmat

\begin{tabular}{|c|c|c|c|c|c|c|c|c|c|c|c|c|c|}
\hline \multirow[b]{2}{*}{ Reference } & \multirow[b]{2}{*}{$\begin{array}{l}\text { Type of study or } \\
\text { algorithm type }\end{array}$} & \multicolumn{3}{|c|}{ Usage } & \multicolumn{4}{|c|}{ Interaction } & \multicolumn{5}{|c|}{ Additional var. } \\
\hline & & 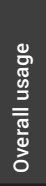 & $\begin{array}{l}\frac{.}{\mathrm{o}} \\
\frac{\mathrm{J}}{\mathrm{J}} \\
\frac{\mathrm{J}}{\mathrm{J}} \\
\frac{\mathrm{J}}{2}\end{array}$ & 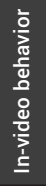 & 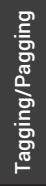 & $\begin{array}{l}\text { 을 } \\
\text { 유 } \\
\text { 흔 }\end{array}$ & 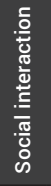 & 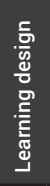 & $\begin{array}{l}\text { 을 } \\
\frac{\pi}{5} \\
\frac{\pi}{5} \\
\text { లँ }\end{array}$ & 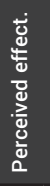 & 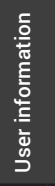 & 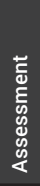 & 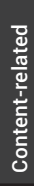 \\
\hline Giannakos, Jaccheri, \& Krogstie, 2015 & Correlation & $\mathrm{V}$ & $\mathrm{V}$ & $\mathrm{V}$ & & & & & & $\mathrm{v}$ & V & & \\
\hline Gkonela \& Chorianopoulus, 2012 & Modelling & $\mathrm{v}$ & $\mathrm{v}$ & $\mathrm{v}$ & & & $\mathrm{v}$ & & & & $\mathrm{v}$ & & $\mathrm{v}$ \\
\hline Grigoras, Charvillat \& Douze, 2002 & Modelling, Regression & $\mathrm{V}$ & $\mathrm{V}$ & $\mathrm{V}$ & & & & & & & & & $\mathrm{V}$ \\
\hline Guo, Kim, \& Rubin, 2014 & Comparison & v & & & & & & $\mathrm{v}$ & & & & $\mathrm{v}$ & $\mathrm{v}$ \\
\hline $\mathrm{He}, 2013$ & Correlation & & & $\mathrm{v}$ & & & $\mathrm{v}$ & & & & & $\mathrm{V}$ & \\
\hline He, Grudin, \& Gupta, 2000 & Modelling, Clustering & $\mathrm{v}$ & & $\mathrm{v}$ & & & & & & & & & \\
\hline He, Sanocki, Gupta, \& Grudin, 2000 & Comparison & $\mathrm{V}$ & & & & & & V & & & & $\mathrm{V}$ & $\mathrm{V}$ \\
\hline Ilioudi, Giannakos, \& Chorianopoulos, 2013 & Comparison & & & & & & v & & $\mathrm{v}$ & & & $\mathrm{v}$ & $\mathrm{V}$ \\
\hline $\begin{array}{l}\text { Kamahara, Nagamatsu, Fukuhara, Kaieda, \& Ishii, } \\
2009\end{array}$ & Modelling & & V & v & & & & & & & & & $\mathrm{V}$ \\
\hline Kim, Guo, Cai, Li, Gajos, \& Miller, 2014 & Modelling, Comparison & $\mathrm{V}$ & $\vee$ & $\mathrm{V}$ & & & & $\mathrm{V}$ & v & 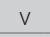 & $\mathrm{V}$ & & $\mathrm{V}$ \\
\hline Kim, Guo, Seaton, Mitros, Gajos, \& Miller 2014 & Modelling, Regression & $\mathrm{V}$ & v & & & & & V & & & & & $\mathrm{V}$ \\
\hline Li, Gupta, Sanoki, He, \& Rui, 2000 & Modelling, Comparison & $\mathrm{v}$ & v & $\mathrm{V}$ & & & & & v & v & & & \\
\hline Li, Kidzinski, Jermann, \& Dillenbourg, 2015 & Modelling, Regression & $\mathrm{V}$ & $\mathrm{v}$ & $\mathrm{V}$ & & & & & & v & & & $\mathrm{v}$ \\
\hline $\begin{array}{l}\text { Li, Zhang, Hu, Zhu, Chen, Jiang, Deng, Guo, Faraco, } \\
\text { Zhang, Han, Hua, \& Liu, } 2010\end{array}$ & Modelling, Comparison & V & & & & & & & & & V & & $\mathrm{v}$ \\
\hline Lyons, Reysen, \& Pierce, 2012 & Comparison & & & & & & & V & v & V & & & $\mathrm{V}$ \\
\hline Mirriahi \& Dawson, 2013 & Correlation & $\mathrm{V}$ & & & & $\mathrm{V}$ & & & & & & $\mathrm{V}$ & \\
\hline Mirriahi, Liaqat, Dawson, \& Gašević, 2016 & Clustering & $\mathrm{V}$ & 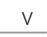 & $\mathrm{V}$ & & V & & & & & & & \\
\hline Monserrat, Zhao, McGee, \& Pendey, 2013 & Comparison & $\mathrm{V}$ & & & & & & & & & $\mathrm{V}$ & $\mathrm{v}$ & $\mathrm{V}$ \\
\hline Mu, 2010 & Comparison & $\mathrm{V}$ & & & & V & & V & & & v & & \\
\hline Pardo, Mirriahi, Dawson, Zhao, Zhao, \& Gašević, 2015 & Correlation, Regression & $\mathrm{V}$ & & & & $\mathrm{V}$ & & & & & $\mathrm{V}$ & $\mathrm{v}$ & \\
\hline Phillips, Maor, Preston, \& Cumming-Potvin, 2011 & Comparison & V & & & & & & & v & v & v & & \\
\hline Risko, Foulsham, Dawson, \& Kingstone, 2013 & Modelling & $\mathrm{v}$ & $\mathrm{v}$ & $\mathrm{v}$ & 0 & $\mathrm{v}$ & & & v & & & & \\
\hline Ritzhaupt, Pastore \& Davis, 2015 & Correlation & & & $\mathrm{V}$ & & & & V & & & & & \\
\hline Samad \& Hamid, 2015 & Modelling, Comparison & $\mathrm{V}$ & & & & & & $\mathrm{V}$ & & & & & \\
\hline Schwan \& Riempp, 2004 & Comparison & & $\mathrm{V}$ & $\mathrm{V}$ & & & & V & & & & V & \\
\hline Shi, Fu, Chen, \& Qu, 2014 & Modelling, Comparison & $\mathrm{V}$ & $\mathrm{v}$ & $\mathrm{V}$ & & & & & & & & & \\
\hline Sinha \& Cassell, 2015 & Modelling, Regression & $\mathrm{V}$ & & & & & & & & & & $\mathrm{v}$ & \\
\hline Song, Hong, Oakley, Cho, \& Bianchi, 2015 & Modelling & $\mathrm{v}$ & & 0 & & & & & & & $\mathrm{v}$ & & \\
\hline Syeda-Mahmood \& Poncelon, 2001 & Clustering & $\mathrm{V}$ & $\mathrm{v}$ & $\mathrm{V}$ & & & & & & & & & $\mathrm{V}$ \\
\hline Vondrick \& Ramanan, 2011 & Correlation & $\mathrm{V}$ & & & & & & $\mathrm{V}$ & & & & & $\mathrm{V}$ \\
\hline Weir, Kim, Gajos, \& Miller, 2015 & Comparison & $\mathrm{V}$ & & & $\mathrm{v}$ & & & & & & & $\mathrm{v}$ & $\mathrm{V}$ \\
\hline Wen \& Rose, 2014 & Clustering & $\mathrm{V}$ & & & & & & & & & & & $\mathrm{V}$ \\
\hline Wieling \& Hofman, 2010 & Correlation, Regression & $\mathrm{V}$ & & & & & & & & & v & & $\mathrm{V}$ \\
\hline Yu, Ma, Nahrstedt, \& Zhang, 2003 & Modelling, Clustering & $\mathrm{V}$ & v & $\mathrm{V}$ & & & & & & & & & $\mathrm{V}$ \\
\hline Zahn, Barquero, \& Schwan, 2004 & Comparison & $\mathrm{v}$ & v & $\mathrm{V}$ & & & & & & & v & $\mathrm{v}$ & $\mathrm{V}$ \\
\hline Zhang, Zhou, Briggs, \& Nunamaker, 2006 & Comparison & v & & & & & & V & & & v & v & $\mathrm{V}$ \\
\hline Zupancic \& Horz, 2002 & Comparison & $\mathrm{V}$ & & & & & & $\mathrm{V}$ & & & $\mathrm{V}$ & $\mathrm{V}$ & $\mathrm{V}$ \\
\hline $\begin{array}{l}\text { NOTES: where 'o' is present, the attribution is subject to interpr } \\
\text { Overall usage refers to counts of activity; Navigation refers to } \\
\text { speed change; Tagging/Flagging is the simple action of markir } \\
\text { fers to the ability to add text or other references to the videos; } \\
\text { to specifically designed conditions, activities, or modes of pres } \\
\text { (i.e. quizzes); User information refers to the availability of user } \\
\text { tent-related means that the input/outputs have a relevance for }\end{array}$ & $\begin{array}{l}\text { wse, search and skip; In-vid } \\
\text { time point which may conta } \\
\text { ial Interaction refers to the } \\
\text { ation; Satisfaction and Perc } \\
\text { tails (i.e. demographics); Ass } \\
\text { e content. }\end{array}$ & 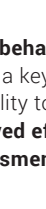 & ectiv & ness & . & tam & $f$ & fur & s; Le & her $\mathrm{i}$ & $\begin{array}{l}\text { warc } \\
\text { nnot } \\
\text { des } \\
\text { n-lin } \\
\text { gra }\end{array}$ & & \\
\hline
\end{tabular}

Giannakos et al. (2014) offered an interesting approach to studying in-video behaviours, testing the affordances of different types of implementation of videos and quiz combinations. The SocialSkip web application (http:// www.socialskip.org) allows instructors to test different scenarios and see the results on students' navigation and performance. In this sense, Kozma's argument that media (and videos in this case) have defining characteristics interacting with the learner, the task characteristics are dependent on the instructional design that employs them and therefore shapes the type of engagement possible with the medium, which can be directly tested with analytics.

\section{Gauging Learning from Usage and En- gagement}

There is evidence that some learners like the opportunities provided by video (Merkt, Weigand, Heier, \& 
Schwan, 2011) and, under certain conditions and with particular designs, videos lead to better learning (using achievement level and grades as proxies for learning) (Giannakos et al., 2014; Mirriahi \& Dawson, 2013). Lab experiments have demonstrated that videos lead to better retention and recall (Mayer, Heiser, \& Lonn, 2001), but the issue of transfer is a serious weakness in most studies. How do we go about demonstrating learning? If more active engagement with content facilitates deep learning, can videos provide this opportunity and, if so, under what conditions?

The discussion about whether it is possible to determine whether learning occurs based on the level of engagement with videos is a tricky one. Earlier we considered simple time on task as an ineffective way to measure engagement. In fact, engagement in learning and teaching can be characterized as having six dimensions (Figure 22.6): intellectual, emotional, behavioural, physical, social, and cultural. The dimensions most relevant when considering the use of videos are strictly intertwined with the nature of use and integration in the curriculum and, therefore, the type of data required to explore engagement for learning is dependent on the learning design and the technology available.
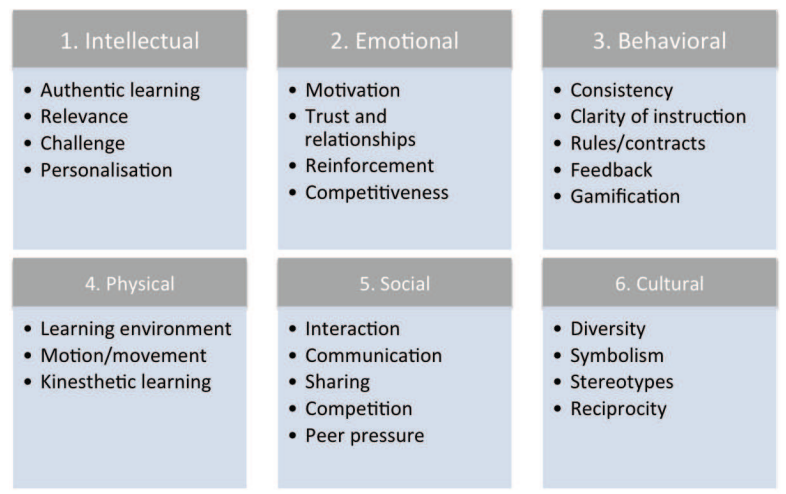

Figure 22.6. Elements of engagement in learning and teaching.

For example, a combination of analytics from learners' use of videos alongside surveys can help capture the metrics related to the intellectual, emotional, and cultural dimensions of learning such as whether they find the videos relevant or challenging and their motivation towards watching them. With the addition of IVQs, feedback and clarity of instruction (the behavioural dimension) can be explored. With the use and sharing of video tagging and annotation, the social dimension can be considered; if videos are used in the classroom, there is opportunity to understand the effects of the physical environment on learning. One of the fundamental problems is the inability to extricate the effect of videos on learning because the proxy of learning is often student performance or achievement demonstrated through assessments external to the video activity (with the exception of IVQs that could be used as summative quizzes assessing content directly related to a video). This poses a challenge for making appropriate judgements on the extent of learning achieved through engagement with videos. Yet, we can rely on the reported levels of satisfaction that learners provide as feedback with the usefulness or effectiveness of videos for their learning, providing a glimpse in their learning experience.

\section{SUMMARY \& FUTURE DIRECTIONS}

The overview provided in this chapter is meant to introduce learning scientists, researchers, educators, and others interested in investigating the impact of videos on learning, use, and engagement to prior approaches that can be adapted to explore new questions and hypothesis.

The chapter has provided an overview of the types of potential videos used for educational purposes and the various ways they can be integrated into the curriculum (although by no means an exhaustive list). Data mining approaches, as one method of analyzing relevant data (alongside more traditional approaches) about learner use, engagement, and learning with videos is discussed with a short summary of approaches reported in recent studies as a starting point for interested readers to explore further as they wish.

This chapter has introduced video analytics and some applications showing how this approach can support the investigation and evaluation of learner engagement and learning with videos. Situating the concept of videos in the curriculum within multimedia learning provides a theoretical foundation for considering the ways in which multimedia (and videos) are included in learning and teaching and how they have historically been evaluated for their effectiveness. As we have seen, a single approach, or "big wrench," may not be as appropriate as a combination of methods and approaches.

Despite the considerable research accrued on the evaluation of the effectiveness of multimedia and videos for learning, many questions remain. Expanding on the studies and strategies to date and leveraging the growing body of data being captured by video technologies provides an opportunity to investigate a milieu of questions not limited to the following:

1. How do learners use, engage with, and learn from different types of videos (e.g., reflection vs. lecture)? A mixed methods approach consisting of video analytics, learner feedback, and instructor reflections and in variety of curriculum or learning 
design contexts would be useful here.

2. What types of interventions can be applied to either a) inform instructors of changes required to video content or how it is integrated in the curriculum or b) inform learners of learning strategies to better engage with the video content or associated activities? Once such interventions are identified, their effectiveness would need to be explored.

3. Rather than relying on proxies of learning (e.g., assessment scores or final marks), how can learning with or from videos be more accurately nuanced?

4. How can data related to video content be better mined in order to explore how it affects learner use and engagement patterns?

5. What are the most effective algorithms for this domain? Is it possible to use some of the models generated to inform instructional design and provide further opportunities to improve learning and the student experience?

\section{REFERENCES}

Antani, S., Kasturi, R., \& Jain, R. (2002). A survey on the use of pattern recognition methods for abstraction, indexing and retrieval of images and video. Pattern Recognition, 35(4), 945-965. http://doi.org/10.1016/ S0031-3203(01)00086-3

Anusha, V., \& Shereen, J. (2014). Multiple lecture video annotation and conducting quiz using random tree classification. International Journal of Engineering Trends and Technology, 8(10), 522-525.

Atkins, M. J. (1993). Theories of learning and multimedia applications: An overview. Research Papers in Education, 8(2), 251-271. http://doi.org/10.1080/0267152930080207

Avlonitis, M., \& Chorianopoulos, K. (2014). Video pulses: User-based modeling of interesting video segments. Advances in Multimedia, 2014. http://doi.org/10.1155/2014/712589

Avlonitis, M., Karydis, I., \& Sioutas, S. (2015). Early prediction in collective intelligence on video users' activity. Information Sciences, 298, 315-329. http://doi.org/10.1016/j.ins.2014.11.039

Beretvas, S. N., Meyers, J. L., \& Leite, W. L. (2002). A reliability generalization study of the Marlowe-Crowne social desirability scale. Educational and Psychological Measurement, 62(4), 570-589. http://doi. org/10.1177/0013164402062004003

Bloom, B. S. (1968). Learning for Mastery: Instruction and Curriculum. Regional Education Laboratory for the Carolinas and Virginia, Topical Papers and Reprints, Number 1. Evaluation Comment, 1(2), n2.

Brooks, C., Epp, C. D., Logan, G., \& Greer, J. (2011). The who, what, when, and why of lecture capture. Proceedings of the 1st International Conference on Learning Analytics and Knowledge (LAK '11), 27 February-1 March 2011, Banff, AB, Canada (pp. 86-92). New York: ACM.

Brunelli, R., Mich, O., \& Modena, C. M. (1999). A survey on the automatic indexing of video data. Journal of Visual Communication and Image Representation, 10(2), 78-112. http://doi.org/10.1006/jvci.1997.0404

Chen, B., Seilhamer, R., Bennett, L., \& Bauer, S. (2015, June 22). Students' mobile learning practices in higher education: A multi-year study. Educause Review. http://er.educause.edu/articles/2015/6/students-mobile-learning-practices-in-higher-education-a-multiyear-study

Chen, L., Chen, G.-C., Xu, C.-Z., March, J., \& Benford, S. (2008). EmoPlayer: A media player for video clips with affective annotations. Interacting with Computers, 20(1), 17-28. http://doi.org/10.1016/j.intcom.2007.06.003

Chorianopoulos, K. (2012). Crowdsourcing user interactions with the video player. Proceedings of the 18th Brazilian Symposium on Multimedia and the Web (WebMedia '12), 15-18 October 2012, São Paulo, Brazil (pp. 13-16). New York: ACM. http://doi.org/10.1145/2382636.2382642

Chorianopoulos, K. (2013). Collective intelligence within web video. Human-Centric Computing and Information Sciences, 3(1), 1-16. http://doi.org/10.1186/2192-1962-3-10

Chorianopoulos, K., Giannakos, M. N., Chrisochoides, N., \& Reed, S. (2014). Open service for video learning analytics. Proceedings of the 14th IEEE International Conference on Advanced Learning Technologies (ICALT 
2014), 7-10 July 2014, Athens, Greece (pp. 28-30). http://doi.org/10.1109/ICALT.2014.19

Clark, R. E. (1983). Reconsidering research on learning from media. Review of Educational Research, 53(4), 445-459. http://doi.org/10.3102/00346543053004445

Clark, R. E. (1994). Media and method. Educational Technology Research and Development, 42(3), 7-10. http:// doi.org/10.1007/BF02298090

Cobârzan, C., \& Schoeffmann, K. (2014). How do users search with basic HTML5 video players? In C. Gurrin, F. Hopfgartner, W. Hurst, H. Johansen, H. Lee, \& N. O'Connor (Eds.), MultiMedia Modeling (pp. 109-120). Springer. http://link.springer.com.wwwproxy0.library.unsw.edu.au/chapter/10.1007/978-3-319-04114-8_10

Colasante, M. (2010). Future-focused learning via online anchored discussion, connecting learners with digital artefacts, other learners, and teachers. Proceedings of the $27^{\text {th }}$ Annual Conference of the Australasian Society for Computers in Learning in Tertiary Education: Curriculum, Technology \& Transformation for an Unknown Future (ASCILITE 2010), 5-8 December 2010, Sydney, Australia (pp. 211-221). ASCILITE.

Colasante, M. (2011). Using video annotation to reflect on and evaluate physical education pre-service teaching practice. Australasian Journal of Educational Technology, 27(1), 66-88.

Coleman, C. A., Seaton, D. T., \& Chuang, I. (2015). Probabilistic use cases: Discovering behavioral patterns for predicting certification. Proceedings of the $2^{\text {nd }}$ ACM conference on Learning@Scale (L@S 2015), 14-18 March 2015, Vancouver, BC, Canada (pp. 141-148). New York: ACM. http://doi.org/10.1145/2724660.2724662

Conole, G. (2013). MOOCs as disruptive technologies: Strategies for enhancing the learner experience and quality of MOOCs. Revista de Educación a Distancia (RED), 39. http://www.um.es/ead/red/39/conole.pdf

Crockford, C., \& Agius, H. (2006). An empirical investigation into user navigation of digital video using the VCR-like control set. International Journal of Human-Computer Studies, 64(4), 340-355. http://doi. org/10.1016/j.ijhcs.2005.08.012

Daniel, R. (2001). Self-assessment in performance. British Journal of Music Education, 18(3). http://doi. org/10.1017/S0265051701000316

Dawson, S., Macfadyen, L., Evan, F. R., Foulsham, T., \& Kingstone, A. (2012). Using technology to encourage self-directed learning: The Collaborative Lecture Annotation System (CLAS). Proceedings of the $29^{\text {th }}$ Annual Conference of the Australasian Society for Computers in Learning in Tertiary Education (ASCILITE 2012), 25-28 October, Wellington, New Zealand (pp. XXX-XXX). ASCILITE. http://www.ascilite.org/conferences/ Wellington12/2012/images/custom/dawson,_shane____using_technology.pdf

de Koning, B. B., Tabbers, H. K., Rikers, R. M. J. P., \& Paas, F. (2011). Attention cueing in an instructional animation: The role of presentation speed. Computers in Human Behavior, 27(1), 41-45. http://doi.org/10.1016/j. chb.2010.05.010

Delen, E., Liew, J., \& Willson, V. (2014). Effects of interactivity and instructional scaffolding on learning: Self-regulation in online video-based environments. Computers \& Education, 78, 312-320. http://doi. org/10.1016/j.compedu.2014.06.018

Diwanji, P., Simon, B. P., Marki, M., Korkut, S., \& Dornberger, R. (2014). Success factors of online learning videos. Proceedings of the International Conference on Interactive Mobile Communication Technologies and Learning (IMCL 2014), 13-14 November 2014, Thessaloniki, Greece (pp. 125-132). IEEE. http://ieeexplore. ieee.org/xpls/abs_all.jsp?arnumber=7011119

Dufour, C., Toms, E. G., Lewis, J., \& Baecker, R. (2005). User strategies for handling information tasks in webcasts. CHI '05 Extended Abstracts on Human Factors in Computing Systems (CHI EA '05), 2-7 April 2005, Portland, OR, USA (pp. 1343-1346). New York: ACM. http://doi.org/10.1145/1056808.1056912

El Samad, A., \& Hamid, O. H. (2015). The role of socio-economic disparities in varying the viewing behavior of e-learners. Proceedings of the $5^{\text {th }}$ International Conference on Digital Information and Communication Technology and its Applications (DICTAP) (pp. 74-79). https://doi.org/10.1109/DICTAP.2015.7113174

Fegade, M. A., \& Dalal, V. (2014). A survey on content based video retrieval. International Journal of Engineering and Computer Science, 3(7), 7271-7279. 
Gagne, R. M. (1965). The conditions of learning. Holt, Rinehart \& Winston.

Gašević, D., Mirriahi, N., \& Dawson, S. (2014). Analytics of the effects of video use and instruction to support reflective learning. Proceedings of the $4^{\text {th }}$ International Conference on Learning Analytics and Knowledge (LAK '14), 24-28 March 2014, Indianapolis, IN, USA (pp. 123-132). New York: ACM. http://doi. org/10.1145/2567574.2567590

Giannakos, M. N. (2013). Exploring the video-based learning research: A review of the literature: Colloquium. British Journal of Educational Technology, 44(6), E191-E195. http://doi.org/10.1111/bjet.12070

Giannakos, M. N., Chorianopoulos, K., \& Chrisochoides, N. (2014). Collecting and making sense of video learning analytics. Proceedings of the 2014 IEEE Frontiers in Education Conference (FIE 2014), 22-25 October 2014, Madrid, Spain. IEEE. http://ieeexplore.ieee.org/xpls/abs_all.jsp?arnumber=7044485

Giannakos, M. N., Chorianopoulos, K., \& Chrisochoides, N. (2015). Making sense of video analytics: Lessons learned from clickstream interactions, attitudes, and learning outcome in a video-assisted course. The International Review of Research in Open and Distributed Learning, 16(1). http://www.irrodl.org/index.php/ irrodl/article/view/1976

Giannakos, M. N., Jaccheri, L., \& Krogstie, J. (2015). Exploring the relationship between video lecture usage patterns and students' attitudes: Usage patterns on video lectures. British Journal of Educational Technology, 47(6), 1259-1275. http://doi.org/10.1111/bjet.12313

Gkonela, C., \& Chorianopoulos, K. (2012). VideoSkip: Event detection in social web videos with an implicit user heuristic. Multimedia Tools and Applications, 69(2), 383-396. http://doi.org/10.1007/s11042-012-1016-1

Gonyea, R. M. (2005). Self-reported data in institutional research: Review and recommendations. New Directions for Institutional Research, 2005(127), 73-89.

Greller, W., \& Drachsler, H. (2012). Translating learning into numbers: A generic framework for learning analytics. Journal of Educational Technology \& Society, 15(3), 42-57.

Grigoras, R., Charvillat, V., \& Douze, M. (2002). Optimizing hypervideo navigation using a Markov decision process approach. Proceedings of the $10^{\text {th }}$ ACM International Conference on Multimedia (MULTIMEDIA '02), 1-6 December 2002, Juan-les-Pins, France (pp. 39-48). New York: ACM. http://doi.org/10.1145/641007.641014

Guo, P. J., Kim, J., \& Rubin, R. (2014). How video production affects student engagement: An empirical study of MOOC videos. Proceedings of the $1^{\text {st }}$ ACM conference on Learning@Scale (L@S 2014), 4-5 March 2014, Atlanta, Georgia, USA (pp. 41-50). New York: ACM. http://doi.org/10.1145/2556325.2566239

Guskey, T. R., \& Good, T. L. (2009). Mastery learning. In T. L. Good (Ed.), 21st Century Education: A Reference Handbook, vol. 1 (pp. 194-202). Thousand Oaks, CA: Sage.

He, W. (2013). Examining students' online interaction in a live video streaming environment using data mining and text mining. Computers in Human Behavior, 29(1), 90-102. http://doi.org/10.1016/j.chb.2012.07.020

He, L., Grudin, J., \& Gupta, A. (2000). Designing presentations for on-demand viewing. Proceedings of the 2000 Conference on Computer Supported Cooperative Work (CSCW '00), 2-6 December 2000, Philadelphia, PA, USA (pp. 127-134). New York: ACM. http://doi.org/10.1145/358916.358983

He, L., Sanocki, E., Gupta, A., \& Grudin, J. (2000). Comparing presentation summaries: Slides vs. reading vs. listening. Proceedings of the SIGCHI Conference on Human Factors in Computing Systems (CHI 2000), 1-6 April 2000, The Hague, Netherlands (pp. 177-184). New York: ACM. http://doi.org/10.1145/332040.332427

Hulsman, R. L., Harmsen, A. B., \& Fabriek, M. (2009). Reflective teaching of medical communication skills with DiViDU: Assessing the level of student reflection on recorded consultations with simulated patients. $\mathrm{Pa}-$ tient Education and Counseling, 74(2), 142-149. http://doi.org/10.1016/j.pec.2008.10.009

Ilioudi, C., Giannakos, M. N., \& Chorianopoulos, K. (2013). Investigating differences among the commonly used video lecture styles. Proceedings of the Workshop on Analytics on Video-Based Learning (WAVe 2013), 8 April 2013, Leuven, Belgium (pp. 21-26). http://ceur-ws.org/Vol-983/WAVe2013-Proceedings.pdf

Johnson, T. (2011, July 22). A few notes from usability testing: Video tutorials get watched, text gets skipped. I'd Rather Be Writing [Blog]. http://idratherbewriting.com/2011/07/22/a-few-notes-from-usability-testing- 
video-tutorials-get-watched-text-gets-skipped/

Joy, E. H., \& Garcia, F. E. (2000). Measuring learning effectiveness: A new look at no-significant-difference findings. Journal of Asynchronous Learning Networks, 4(1), 33-39.

Juhlin, O., Zoric, G., Engström, A., \& Reponen, E. (2014). Video interaction: A research agenda. Personal and Ubiquitous Computing, 18(3), 685-692. http://doi.org/10.1007/s00779-013-0705-8

Kamahara, J., Nagamatsu, T., Fukuhara, Y., Kaieda, Y., \& Ishii, Y. (2009). Method for identifying task hardships by analyzing operational logs of instruction videos. In T.-S. Chua, Y. Kompatsiaris, B. Mérialdo, W. Haas, G. Thallinger, \& W. Bailer (Eds.), Semantic Multimedia (pp. 161-164). Springer. http://link.springer.com.wwwproxy0.library.unsw.edu.au/chapter/10.1007/978-3-642-10543-2_16

Keller, F. S. (1967). Engineering personalized instruction in the classroom. Revista Interamericana de Psicologia, 1(3), 144-156.

Kim, J., Guo, P. J., Cai, C. J., Li, S.-W. (Daniel), Gajos, K. Z., \& Miller, R. C. (2014). Data-driven Interaction Techniques for Improving Navigation of Educational Videos. In Proceedings of the $27^{\text {th }}$ Annual ACM Symposium on User Interface Software and Technology (pp. 563-572). New York, NY, USA: ACM. https://doi. org/10.1145/2642918.2647389

Kim, J., Guo, P. J., Seaton, D. T., Mitros, P., Gajos, K. Z., \& Miller, R. C. (2014). Understanding in-video dropouts and interaction peaks in online lecture videos. Proceedings of the $1^{\text {st }}$ ACM Conference on Learning @ Scale (L@S 2014), 4-5 March 2014, Atlanta, GA, USA (pp. 31-40). New York: ACM. http://doi. org/10.1145/2556325.2566239

Kirschner, P. A., Sweller, J., \& Clark, R. E. (2006). Why minimal guidance during instruction does not work: An analysis of the failure of constructivist, discovery, problem-based, experiential, and inquiry-based teaching. Educational Psychologist, 41(2), 75-86. http://doi.org/10.1207/s15326985ep4102_1

Kolowich, S. (2013, March 18). The professors who make the MOOCs. The Chronicle of Higher Education, 25. http://www.chronicle.com/article/The-Professors-Behind-the-MOOC/137905/

Kozma, R. B. (1991). Learning with media. Review of Educational Research, 61(2), 179-211. http://doi. org/10.3102/00346543061002179

Kozma, R. B. (1994). Will media influence learning? Reframing the debate. Educational Technology Research and Development, 42(2), 7-19. http://doi.org/10.1007/BF02299087

Kulik, C.-L. C., Kulik, J. A., \& Bangert-Drowns, R. L. (1990). Effectiveness of mastery learning programs: A meta-analysis. Review of Educational Research, 60(2), 265-299. http://doi.org/10.3102/00346543060002265

Lee, H. S., \& Anderson, J. R. (2013). Student learning: What has instruction got to do with it? Annual Review of Psychology, 64(1), 445-469. http://doi.org/10.1146/annurev-psych-113011-143833

Li, F. C., Gupta, A., Sanocki, E., He, L., \& Rui, Y. (2000). Browsing digital video. Proceedings of the SIGCHI Conference on Human Factors in Computing Systems (CHI 2000), 1-6 April 2000, The Hague, Netherlands (pp. 169-176). New York: ACM. http://doi.org/10.1145/332040.332425

Li, N., Kidzinski, L., Jermann, P., \& Dillenbourg, P. (2015). How do in-video interactions reflect perceived video difficulty? Proceedings of the $3^{\text {rd }}$ European MOOCs Stakeholder Summit, 18-20 May 2015, Mons, Belgium (pp. 112-121). PAU Education. http://infoscience.epfl.ch/record/207968

Li, K., T. Zhang, X. Hu, D. Zhu, H. Chen, X. Jiang, F. Deng, J. Lv, C. C. Faraco, and D. Zhang. 2010. "Human-Friendly Attention Models for Video Summarization." In International Conference on Multimodal Interfaces and the Workshop on Machine Learning for Multimodal Interaction (pp. 27:1-27:8). New York: ACM. http://doi.org/10.1145/1891903.1891938

Lyons, A., Reysen, S., \& Pierce, L. (2012). Video lecture format, student technological efficacy, and social presence in online courses. Computers in Human Behavior, 28(1), 181-186. http://doi.org/10.1016/j. chb.2011.08.025

Margaryan, A., Bianco, M., \& Littlejohn, A. (2015). Instructional quality of Massive Open Online Courses (MOOCs). Computers E Education, 80, 77-83. http://doi.org/10.1016/j.compedu.2014.08.005 
Mayer, R. E. (2009). Multimedia learning. Cambridge, UK: Cambridge University Press.

Mayer, R. E., Heiser, J., \& Lonn, S. (2001). Cognitive constraints on multimedia learning: When presenting more material results in less understanding. Journal of Educational Psychology, 93(1), 187-198. http://doi. org/10.1037/0022-0663.93.1.187

McKeachie, W. J. (1974). Instructional psychology. Annual Review of Psychology, 25(1), 161-193. http://doi. org/10.1146/annurev.ps.25.020174.001113

Merkt, M., Weigand, S., Heier, A., \& Schwan, S. (2011). Learning with videos vs. learning with print: The role of interactive features. Learning and Instruction, 21(6), 687-704. http://doi.org/10.1016/j.learninstruc.2011.03.004

Mirriahi, N., \& Dawson, S. (2013). The pairing of lecture recording data with assessment scores: A method of discovering pedagogical impact. Proceedings of the $3^{\text {rd }}$ International Conference on Learning Analytics and Knowledge (LAK '13), 8-12 April 2013, Leuven, Belgium (pp. 180-184). New York: ACM. http://dl.acm.org/citation.cfm?id=2460331

Mirriahi, N., Liaqat, D., Dawson, S., \& Gašević, D. (2016). Uncovering student learning profiles with a video annotation tool: Reflective learning with and without instructional norms. Educational Technology Research and Development, 64(6), 1083-1106. http://doi.org/10.1007/s11423-016-9449-2

Monserrat, T.-J. K. P., Zhao, S., McGee, K., \& Pandey, A. V. (2013). NoteVideo: Facilitating navigation of Blackboard-style lecture videos. Proceedings of the SIGCHI Conference on Human Factors in Computing Systems (CHI '13), 27 April-2 May 2013, Paris, France (pp. 1139-1148). New York: ACM. http://doi. org/10.1145/2470654.2466147

$\mathrm{Mu}, \mathrm{X}$. (2010). Towards effective video annotation: An approach to automatically link notes with video content. Computers \& Education, 55(4), 1752-1763. http://doi.org/10.1016/j.compedu.2010.07.021

Oblinger, D. G., \& Hawkins, B. L. (2006). The myth about no significant difference. EDUCAUSE Review, 41(6), $14-15$.

Owston, R., Lupshenyuk, D., \& Wideman, H. (2011). Lecture capture in large undergraduate classes: Student perceptions and academic performance. The Internet and Higher Education, 14(4), 262-268. http://doi. org/10.1016/j.iheduc.2011.05.006

Palincsar, A. S. (1998). Social constructivist perspectives on teaching and learning. Annual Review of Psychology, 49(1), 345-375. http://doi.org/10.1146/annurev.psych.49.1.345

Pardo, A., Mirriahi, N., Dawson, S., Zhao, Y., Zhao, A., \& Gašević, D. (2015). Identifying learning strategies associated with active use of video annotation software. Proceedings of the $5^{\text {th }}$ International Conference on Learning Analytics and Knowledge (LAK '15), 16-20 March 2015, Poughkeepsie, NY, USA (pp. 255-259). New York: ACM Press. http://doi.org/10.1145/2723576.2723611

Peña-Ayala, A. (2014). Educational data mining: A survey and a data mining-based analysis of recent works. Expert Systems with Applications, 41(4, Part 1), 1432-1462. http://doi.org/10.1016/j.eswa.2013.08.042

Phillips, R., Maor, D., Cumming-Potvin, W., Roberts, P., Herrington, J., Preston, G., ... Perry, L. (2011). Learning analytics and study behaviour: A pilot study. In G. Williams, P. Statham, N. Brown, \& B. Cleland (Eds.), Proceedings of the $28^{\text {th }}$ Annual Conference of the Australasian Society for Computers in Learning in Tertiary Education: Changing Demands, Changing Directions (ASCILITE 2011), 4-7 December 2011, Hobart, Tasmania, Australia (pp. 997-1007). ASCILITE. http://researchrepository.murdoch.edu.au/6751/

Reeves, T. C. (1986). Research and evaluation models for the study of interactive video. Journal of Computer-Based Instruction, 13(4), 102-106.

Reeves, T. C. (1991). Ten commandments for the evaluation of interactive multimedia in higher education. Journal of Computing in Higher Education, 2(2), 84-113. http://doi.org/10.1007/BF02941590

Risko, E. F., Foulsham, T., Dawson, S., \& Kingstone, A. (2013). The collaborative lecture annotation system (CLAS): A new TOOL for distributed learning. IEEE Transactions on Learning Technologies, 6(1), 4-13. http:// doi.org/10.1109/TLT.2012.15 
Ritzhaupt, A. D., Pastore, R., \& Davis, R. (2015). Effects of captions and time-compressed video on learner performance and satisfaction. Computers in Human Behavior, 45, 222-227. http://doi.org/10.1016/j. chb.2014.12.020

Romero, C., \& Ventura, S. (2007). Educational data mining: A survey from 1995 to 2005. Expert Systems with Applications, 33(1), 135-146.

Romero, C., \& Ventura, S. (2010). Educational data mining: A review of the state of the art. IEEE Transactions on Systems, Man, and Cybernetics, Part C: Applications and Reviews, 40(6), 601-618. https://doi. org/10.1109/TSMCC.2010.2053532

Russell, T. L. (1999). The no significant difference phenomenon: A comparative research annotated bibliography on technology for distance education: As reported in 355 research reports, summaries and papers. North Carolina State University.

Schwan, S., \& Riempp, R. (2004). The cognitive benefits of interactive videos: Learning to tie nautical knots. Learning and Instruction, 14(3), 293-305. http://doi.org/10.1016/j.learninstruc.2004.06.005

Shi, C., Fu, S., Chen, Q., \& Qu, H. (2014). VisMOOC: Visualizing video clickstream data from massive open online courses. Proceedings of the 2014 IEEE Conference on Visual Analytics Science and Technology (VAST 2014), 9-14 November 2014, Paris, France (pp. 277-278). IEEE. http://ieeexplore.ieee.org/xpls/abs_all.jsp?arnumber $=7042528$

Sinha, T., \& Cassell, J. (2015). Connecting the dots: Predicting student grade sequences from Bursty MOOC interactions over time. Proceedings of the $2^{\text {nd }}$ ACM Conference on Learning@Scale (L@S 2015), 14-18 March 2015, Vancouver, BC, Canada (pp. 249-252). New York: ACM. http://doi.org/10.1145/2724660.2728669

Skinner, F. B. (1950). Are theories of learning necessary? Psychological Review, 57(4), 193-216. http://doi. org/10.1037/h0054367

Song, S., Hong, J., Oakley, I., Cho, J. D., \& Bianchi, A. (2015). Automatically adjusting the speed of e-learning videos. CHI $33^{\text {rd }}$ Conference on Human Factors in Computing Systems: Extended Abstracts (CHI EA '15), 18-23 April 2015, Seoul, Republic of Korea (pp. 1451-1456). New York: ACM. http://doi.org/10.1145/2702613.2732711

Syeda-Mahmood, T., \& Ponceleon, D. (2001). Learning video browsing behavior and its application in the generation of video previews. Proceedings of the $9^{\text {th }}$ ACM International Conference on Multimedia (MULTIMEDIA '01), 30 September-5 October 2001, Ottawa, ON, Canada (pp. 119-128). New York: ACM. http://doi. org/10.1145/500141.500161

Tennyson, R. D. (1994). The big wrench vs. integrated approaches: The great media debate. Educational Technology Research and Development, 42(3), 15-28. http://doi.org/10.1007/BF02298092

Vondrick, C., \& Ramanan, D. (2011). Video annotation and tracking with active learning. In J. Shawe-Taylor, R. S. Zemel, P. L. Bartlett, F. Pereira, K. Q. Weinberger (Eds.), Advances in Neural Information Processing Systems 24 (NIPS 2011), 12-17 December 2011, Granada, Spain (pp. 28-36). http://papers.nips.cc/paper/4233-video-annotation-and-tracking-with-active-learning

Weir, S., Kim, J., Gajos, K. Z., \& Miller, R. C. (2015). Learnersourcing subgoal labels for how-to videos. Proceedings of the $18^{\text {th }}$ ACM Conference on Computer Supported Cooperative Work E Social Computing (CSCW '15), 14-18 March 2015, Vancouver, BC, Canada (pp. 405-416). New York: ACM. http://doi. org/10.1145/2675133.2675219

Wen, M., \& Rosé, C. P. (2014). Identifying latent study habits by mining learner behavior patterns in massive open online courses. Proceedings of the $23^{\text {rd }}$ ACM International Conference on Conference on Information and Knowledge Management (CIKM '14), 3-7 November 2014, Shanghai, China (pp. 1983-1986). New York: ACM. http://doi.org/10.1145/2661829.2662033

Wieling, M. B., \& Hofman, W. H. A. (2010). The impact of online video lecture recordings and automated feedback on student performance. Computers E Education, 54(4), 992-998. http://doi.org/10.1016/j.compedu.2009.10.002

Winne, P. H., \& Jamieson-Noel, D. (2002). Exploring students' calibration of self reports about study tactics and achievement. Contemporary Educational Psychology, 27(4), 551-572. 
Witten, I. H., \& Frank, E. (2005). Data mining: Practical machine learning tools and techniques. Burlington, MA: Morgan Kaufmann Publishers.

Yousef, A. M. F., Chatti, M. A., \& Schroeder, U. (2014). Video-based learning: A critical analysis of the research published in 2003-2013 and future visions. Proceedings of the $6^{\text {th }}$ International Conference on Mobile, Hybrid, and On-line Learning (ThinkMind/eLmL 2014), 23-27 March 2014, Barcelona, Spain (pp. 112-119). http://www.thinkmind.org/index.php?view=article\&articleid=elml_2014_5_30_50050

Yu, B., Ma, W.-Y., Nahrstedt, K., \& Zhang, H.-J. (2003). Video summarization based on user log enhanced link analysis. Proceedings of the $11^{\text {th }}$ ACM International Conference on Multimedia (MULTIMEDIA '03), 2-8 November 2003, Berkeley, CA, USA (pp. 382-391). New York: ACM. http://doi.org/10.1145/957013.957095

Zahn, C., Barquero, B., \& Schwan, S. (2004). Learning with hyperlinked videos: Design criteria and efficient strategies for using audiovisual hypermedia. Learning and Instruction, 14(3), 275-291. http://doi. org/10.1016/j.learninstruc.2004.06.004

Zhang, D., Zhou, L., Briggs, R. O., \& Nunamaker Jr., J. F. (2006). Instructional video in e-learning: Assessing the impact of interactive video on learning effectiveness. Information $\&$ Management, 43(1), 15-27. http://doi. org/10.1016/j.im.2005.01.004

Zupancic, B., \& Horz, H. (2002). Lecture recording and its use in a traditional university course. In Proceedings of the $7^{\text {th }}$ Annual Conference on Innovation and Technology in Computer Science Education (ITiCSE '02), 24-28 June 2002, Aarhus, Denmark (pp. 24-28). New York: ACM. http://doi.org/10.1145/544414.544424 